\title{
PENGARUH KARAKTERISTIK RUMAH TANGGA TERHADAP TINGKAT \\ KEMISKINAN MASYARAKAT SEKITAR MANGROVE \\ (Kasus di Desa Sidodadi Kecamatan Teluk Pandan Kabupaten Pesawaran)
}

\section{INFLUENCE OF HOUSEHOLD CHARACTERISTICS ON COMMUNITIES POVERTY LINE IN SURROUNDING MANGROVE \\ (A Case in Sidodadi Village Teluk Pandan Sub-District Pesawaran District)}

\author{
Afrian Andrianto, Rommy Qurniati dan Agus Setiawan \\ Jurusan Kehutanan Fakultas Pertanian Universitas Lampung \\ Jl. Soemantri Brojonegoro No.1 Bandar Lampung \\ E-mail: afrianandrianto@gmail.com \\ Phone: 082280582853
}

\begin{abstract}
ABSTRAK
Ekosistem hutan mangrove adalah salah satu sumber daya pesisir yang berperan penting dalam aspek sosial, ekonomi dan ekologi. Namun, pada kenyataanya masih banyak masyarakat pesisir yang berada dalam kondisi miskin. Penelitian ini bertujuan untuk menganalisis tingkat kemiskinan rumah tangga dan menentukan karakteristik rumah tangga yang berpengaruh terhadap tingkat kemiskinan. Penelitian ini dilakukan pada bulan Januari sampai Maret 2015. Penentuan responden dilakukan secara sampel acak sederhana dan diperoleh jumlah sebanyak 71 responden. Metode pengumpulan data yang digunakan adalah wawancara langsung kepada responden menggunakan kuesioner. Hasil penelitian menunjukkan bahwa sebagian masyarakat berada di bawah garis kemiskinan. Kemiskinan yang terjadi tidak dipengaruhi oleh umur, jenis pekerjaan, kesehatan, suku/etnis dan kondisi rumah. Karakteristik rumah tangga yang berpengaruh terhadap kemiskinan adalah pendidikan, pendapatan, jumlah anggota keluarga yang bekerja dan fasilitas rumah. Rumah tangga tidak banyak memiliki alternatif sumber pendapatan dari hutan mangrove akibat rendahnya pengetahuan masyarakat mengenai pemanfaatan hasil hutan bukan kayu dari mangrove.
\end{abstract}

Kata kunci: Hutan mangrove, karakteristik rumah tangga, tingkat kemiskinan

\begin{abstract}
The mangrove forest ecosystem is one of the coastal resources that give an important role in social, economic and ecological aspects. In fact, there are many coastal communities in poverty conditions. This study intended to analyze household poverty line and influence of household characteristics on poverty line. This study has conducted from January to March 2015. Determination of respondents was done in simple random sampling and was obtained 71 respondents. Data collection method was used structural interview to respondents. The results showed that partly of communities were categories in the poverty line. Poverty line was not affected by age, work types, health, ethnic and houses condition. Household characteristics that have an influence on the poverty line were education, income, number of working family members and houses facilities. Households have less alternative source of income from mangrove forests caused by lack of knowledge about utilization of non timber forest products from the mangrove.
\end{abstract}

Keywords: Household characteristics, mangrove, poverty line 


\section{PENDAHULUAN}

Hutan mangrove adalah ekosistem hutan yang terdapat di daerah pantai yang secara teratur digenangi oleh air laut atau dipengaruhi oleh pasang surut air laut, dengan kondisi tanah berlumpur atau lumpur berpasir (Indriyanto, 2008). Ekosistem hutan mangrove adalah salah satu sumber daya pesisir yang berperan penting dalam aspek sosial, ekonomi dan ekologi sehingga mampu memberikan kontribusi bagi masyarakat pesisir (Patang, 2012). Namun, pada kenyataanya hak-hak dasar seperti pangan, kesehatan, pendidikan, pekerjaan dan kondisi tempat tinggal masyarakat pesisir belum terpenuhi, akibatnya masih banyak masyarakat yang berada dalam kondisi miskin (Sugiharto, 2007). Kondisi tersebut tentu sebuah ironi ditengah besarnya potensi wilayah pesisir yang seharusnya dapat dimanfaatkan masyarakat dalam memperbaiki kondisi ekonomi.

Desa Sidodadi merupakan desa yang berdekatan dengan daerah pesisir pantai. Kondisi tersebut menyebabkan sebagian besar masyarakat yang bertempat tinggal di wilayah pesisir bermata pencaharian sebagai nelayan. Masyarakat nelayan tersebut merupakan nelayan yang bekerja dengan alat tangkap milik orang lain (nelayan buruh) sehingga kondisi ekonomi masyarakat dapat dikatakan rendah (miskin). Selain itu terdapat masyarakat yang memanfaatkan lahan pertanian sebagai mata pencahariannya dengan cara bercocok tanam.

Kondisi ekonomi masyarakat yang rendah disebabkan kurangnya keterampilan dalam sektor perikanan, sarana dan prasarana pendukung usaha, belum dioptimalkan sumber daya alam lain di luar sektor perikanan dan pengaruh budaya. Untuk memperbaiki kondisi tersebut maka perlu dianalisis pengaruh karakteristik rumah tangga terhadap kemiskinan masyarakat pesisir.

\section{METODE PENELITIAN}

Penelitian ini dilaksanakan di Desa Sidodadi Kecamatan Teluk Pandan Kabupaten Pesawaran pada bulan Januari sampai Maret 2015. Desa Sidodadi memiliki keunikan karena terletak diantara daerah pesisir pantai yang memiliki hutan mangrove dan Taman Hutan Raya Wan Abdul Rahman (Tahura WAR). Populasi penelitian adalah rumah tangga yang tinggal berdekatan dengan hutan mangrove. Rumah tangga yang tinggal berbatasan dengan hutan mangrove berjumlah 243 kepala keluarga. Pengambilan sampel dilakukan secara simple random sampling dan diperoleh sampel sebanyak 71 kepala rumah tangga. Data yang dikumpulkan dalam penelitian ini adalah data primer yang diperoleh dengan cara observasi dan wawancara langsung kepada responden menggunakan kuesioner dan data sekunder diperoleh melalui studi pustaka dari instansi yang berkaitan dengan penelitian.

Tingkat kemiskinan rumah tangga diukur menggunakan indikator kemiskinan Sajogyo (2006) berdasarkan konsumsi/pengeluaran setara nilai tukar beras/orang/tahun. Total konsumi/pengeluaran rumah tangga yang terdiri dari pangan dan non pangan dalam setahun dibagi dengan jumlah tanggungan keluarga. Hasil konsumsi rumah tangga setara nilai tukar beras/orang/tahun kemudian dibagi dengan harga atau nilai beras per kilogram setempat. Besarnya konsumsi/pengeluaran rumah tangga setara nilai tukar beras/orang/tahun, antara lain sebagai berikut.

1. Paling miskin, apabila konsumsi/pengeluaran rumah tangga $\leq 180 \mathrm{~kg}$ setara nilai beras/orang/tahun.

2. Miskin sekali, apabila konsumsi/pengeluaran rumah tangga antara 181-240 kg setara nilai beras/orang/tahun.

3. Miskin, apabila konsumsi/pengeluaran rumah tangga antara 241-320 kg setara nilai beras/orang/tahun. 
4. Tidak miskin, apabila konsumsi/pengeluaran rumah tangga $\geq 321 \mathrm{~kg}$ setara nilai beras/orang/tahun.

Karakteristik rumah tangga yang terdiri dari umur, pendidikan kepala keluarga, jenis pekerjaan, pendapatan, jumlah anggota keluarga yang bekerja, kesehatan, suku/etnis, kondisi rumah dan fasilitas rumah diduga berpengaruh terhadap tingkat kemiskinan rumah tangga. Karakteristik tersebut akan dianalisis secara kualitatif dan diuji secara kuantitatif menggunakan Analisis Regresi Logistik Ordinal dan untuk pengujian parameter yang digunakan Uji Serentak dan Uji Parsial pada taraf nyata $\alpha=5 \%$ dan $10 \%$.

\section{HASIL DAN PEMBAHASAN}

\section{Tingkat Kemiskinan}

Kemiskinan dipandang sebagai ketidakmampuan dari sisi ekonomi untuk memenuhi kebutuhan dasar pangan dan non pangan yang diukur dari garis kemiskinan (Pratama, 2014). Pengukuran tingkat kemiskinan dilakukan dengan cara menghitung konsumsi/pengeluaran rumah tangga setara nilai tukar beras/orang/tahun untuk menentukan garis kemiskinan. Berdasarkan konsep garis kemiskinan Sajogyo agar rumah tangga didaerah penelitian dapat dikatakan "tidak miskin" maka rumah tangga harus memiliki rata-rata pendapatan sebesar Rp 11.529.036/tahun. Nilai tersebut didapatkan dengan mengalikan tiga faktor yang mempengaruhi tingkat kemiskinan berdasarkan konsep garis kemiskinan Sajogyo, yaitu batas minimal konsumsi/pengeluaran diatas garis kemiskinan ( $2321 \mathrm{~kg}$ ), rata-rata jumlah anggota keluarga (4 orang) dan rata-rata harga/nilai beras setempat pada saat penelitian ( $R p$ 8.979). Penggolongan tingkat kemiskinan rumah tangga menurut konsep garis kemiskinan Sajogyo dapat dilihat pada Tabel 1.

Tabel 1. Tingkat kemiskinan rumah tangga Desa Sidodadi tahun 2015.

\begin{tabular}{rlrrr}
\hline No. & Kategori & Indikator $(\mathbf{k g} / \mathbf{t h})$ & Jumlah responden & Persentase $(\boldsymbol{\%})$ \\
\hline 1. & Paling miskin & $\leq 180$ & $13^{*}$ & $18^{*}$ \\
2. Miskin sekali & $181-240$ & $12^{*}$ & $17^{*}$ \\
3. & Miskin & $71-320$ & $7^{*}$ & $10^{*}$ \\
4. & Tidak miskin & $\geq 321$ & 39 & 55 \\
\hline \multicolumn{2}{l}{ Total } & & $\mathbf{7 1}$ & $\mathbf{1 0 0}$ \\
\hline
\end{tabular}

Sumber: Data primer diolah (2015).

Catatan: * (dibawah garis kemiskinan).

Berdasarkan penggolongan tingkat kemiskinan rumah tangga (Tabel 1), jumlah rumah tangga yang berada di bawah garis kemiskinan adalah sebanyak 32 KK (45\%), jumlah tersebut diperoleh dari kategori paling miskin, miskin sekali dan miskin. Rumah tangga yang berada dibawah garis kemiskinan disebabkan oleh rendahnya pendapatan dan cenderung tidak menentu setiap saat yang berujung pada sulitnya mengakses pendidikan dan kesehatan yang layak, sehingga menyebabkan lemahnya daya saing rumah tangga miskin dalam memperebutkan peluang kerja yang lebih layak secara ekonomi. Kualitas modal manusia yang masih rendah, tingkat pendidikan yang masih terbatas serta tidak dimilikinya keterampilan kerja yang memadai menyebabkan tenaga kerja tidak bisa mengakses peluang kerja yang lebih baik. 


\section{Pengaruh Karakteristik Rumah Tangga terhadap Tingkat Kemiskinan}

Analisis regresi logistik ordinal digunakan untuk mengetahui faktor-faktor yang mempengaruhi tingkat kemiskinan. Berdasarkan hasil analisis didapatkan estimasi sebagai berikut.

Tabel 2. Hasil estimasi karakteristik rumah tangga terhadap tingkat kemiskinan

\begin{tabular}{|c|c|c|c|c|c|}
\hline Prediksi & Koefisien & $\mathbf{Z}$ & P-value & Odds Ratio & Keterangan \\
\hline Konstanta (1) & 7,924 & 2,75 & 0,006 & & \\
\hline Konstanta (2) & 10,350 & 3,35 & 0,001 & & \\
\hline Konstanta (3) & 11,890 & 3,71 & 0,001 & & \\
\hline Umur & 0,013 & 0,43 & 0,668 & 1,01 & Tidak signifikan \\
\hline \multicolumn{6}{|l|}{ Tingkat Pendidikan } \\
\hline$(2=\mathrm{SMP})$ & 0,291 & 0,33 & 0,741 & 0,75 & Tidak signifikan \\
\hline (3 = SMA) & 1,924 & 2,11 & 0,035 & 0,15 & Signifikan \\
\hline Pekerjaan & $-0,226$ & $-0,24$ & 0,809 & 0,80 & Tidak signifikan \\
\hline Pendapatan & $-0,001$ & $-4,78$ & 0,001 & 1,00 & Signifikan \\
\hline Jumlah anggota keluarga yang bekerja & $-2,625$ & $-2,21$ & 0,027 & 0,07 & Signifikan \\
\hline Kesehatan & $-0,793$ & $-1,16$ & 0,247 & 0,45 & Tidak signifikan \\
\hline Suku/etnis & $-0,576$ & $-0,79$ & 0,429 & 0,56 & Tidak signifikan \\
\hline \multicolumn{6}{|l|}{ Kondisi rumah } \\
\hline$(2=$ Semi permanen $)$ & $-0,548$ & $-0,56$ & 0,577 & 0,58 & Tidak signifikan \\
\hline$(3=$ Permanen $)$ & 0,454 & 0,48 & 0,628 & 1,57 & Tidak signifikan \\
\hline \multicolumn{6}{|l|}{ Fasilitas rumah } \\
\hline ( 2 = Semi lengkap $)$ & $-2,074$ & $-1,85$ & 0,064 & 0,13 & Signifikan \\
\hline (3 = Lengkap) & 0,227 & 0,28 & 0,781 & 1,25 & Tidak signifikan \\
\hline
\end{tabular}

Sumber: Data primer diolah (2015).

Hasil uji secara serentak menggunakan tes Log-Likelihood dihasilkan nilai uji statistik G sebesar 85,400 dengan p-value sebesar 0,001, maka dapat disimpulkan bahwa dengan pengujian secara serentak pengaruh variabel karakteristik rumah tangga terhadap tingkat kemiskinan signifikan. Artinya, terdapat minimal satu variabel karakteristik rumah tangga yang berpengaruh terhadap tingkat kemiskinan.

Pengujian secara parsial atau individu digunakan untuk mengetahui variabel karakteristik rumah tangga yang berpengaruh signifikan secara individu. Pengujian dilakukan dengan nilai statistik uji Z, jika nilai uji Z lebih besar dari tabel $\mathrm{Z}$ atau $p$-value lebih kecil dari $a=5 \%$ dan $10 \%$ maka variabel tersebut berpengaruh secara signifikan.

Secara parsial atau individu variabel yang berpengaruh secara signifikan pada taraf $a=$ $5 \%$ adalah pendidikan, pendapatan, jumlah anggota keluarga yang bekerja dan variabel yang berpengaruh secara signifikan pada taraf $a=10 \%$ adalah fasilitas rumah. Variabel yang tidak berpengaruh secara signifikan pada taraf $a=5 \%$ dan $a=10 \%$ adalah umur, jenis pekerjaan, kesehatan, suku/etnis dan kondisi rumah. Hal ini sejalan dengan pendapat Kornita dan Yusbar (2011) yang menyatakan bahwa karakteristik rumah tangga miskin dapat ditinjau dari aspek ekonomi seperti tingkat pendapatan dan mata pencaharian sedangkan aspek sosial dapat ditinjau dari umur, tingkat pendidikan, pekerjaan, jumlah anggota keluarga yang bekerja, kesehatan, suku, fasilitas dan kondisi rumah.

Tingkat pendidikan masyarakat masih tergolong rendah, hal ini dikarenakan sebagian besar pendidikan kepala rumah tangga di Desa Sidodadi adalah Sekolah Dasar/SD (48\%), tingkat pendidikan masyarakat belum memenuhi standar pendidikan dasar nasional yaitu wajib belajar 9 tahun atau minimal menyelesaikan pendidikan SMP. Kaplale (2012) menjelaskan bahwa pendidikan secara tidak langsung memengaruhi pola pikir kepala keluarga, semakin tinggi jenjang pendidikan yang pernah dilalui maka semakin tinggi pula motivasi yang terlihat pada perilaku untuk mencapai suatu tingkat pendapatan tertentu. Hal 
tersebut memberikan gambaran bahwa semakin tinggi tingkat pendidikan yang dicapai kepala keluarga, maka memiliki peluang untuk keluar dari tingkat kemiskinan. Hasil penelitian ini didukung oleh penelitian Iskandar (2007) yang menyatakan bahwa tingkat pendidikan memengaruhi kesempatan bagi seseorang untuk memilih jenis pekerjaan guna memenuhi kebutuhan hidupnya.

Faktor ekonomi biasanya berkaitan dengan kemampuan keluarga dalam memperoleh pendapatan (Wijayanti, 2013). Pendapatan merupakan hal terpenting dalam kehidupan, khususnya rumah tangga untuk pemenuhan kebutuhan hidup terutama kebutuhan pangan (Aminah, 2013). Pendapatan rumah tangga di Desa Sidodadi berkisar antara Rp 500.000 Rp 5.000.000/bulan atau rata-rata Rp 1.777.465/bulan. Pendapatan tersebut terbagi atas; pendapatan dari pemanfaatan hutan mangrove (ikan, kerang dan kepiting) dan pendapatan di luar pemanfaatan hutan mangrove (buruh, petani maupun pedagang). Pemanfaatan hutan mangrove yang dilakukan masyarakat hanya berupa biota lautnya saja, masyarakat belum memiliki pengetahuan mengenai pemanfaatan lain hutan mangrove yaitu buah mangrove yang dapat diolah menjadi berbagai macam panganan seperti; dodol, sirup, kerupuk dan keripik yang dapat dipasarkan untuk memperoleh pendapatan bagi masyarakat (Wahyukinasih, 2014). Hasil analisis data Tabel 2 menunjukkan bahwa apabila terjadi penurunan pada pendapatan rumah tangga, maka akan menurunkan daya beli rumah tangga yang pada akhirnya akan meningkatkan kemiskinan. Hasil penelitian ini didukung oleh penelitian Iskandar (2007) yang menyatakan bahwa pendapatan rumah tangga akan menentukkan daya beli terhadap pangan, non pangan dan fasilitas pendukung lainnya.

Jumlah anggota keluarga yang bekerja adalah jumlah orang yang bekerja dalam satu rumah tangga. Peran anggota keluarga yang bekerja sangat membantu dalam meningkatkan pendapatan keluarga (Agunggunanto, 2011). Terdapat 18\% rumah tangga yang memiliki lebih dari satu anggota keluarga yang bekerja. Selain kepala rumah tangga terdapat istri dan atau anak dewasa ( $\geq 18$ tahun) yang bekerja. Umumnya besar jumlah tanggungan keluarga memengaruhi jumlah anggota keluarga yang bekerja akibat tingginya pemenuhan kebutuhan yang harus dipenuhi dalam keluarga. Hasil analisis data Tabel 2 menunjukkan bahwa semakin sedikit jumlah anggota keluarga yang bekerja maka akan meningkatkan kemiskinan. Hasil ini memberikan gambaran bahwa semakin bertambah jumlah anggota keluarga yang bekerja maka dapat membantu perekonomian keluarga seiring dengan kebutuhan hidup yang harus dipenuhi (Purwanti, 2014).

Fasilitas rumah dalam penelitian ini dilihat dari beberapa tolak ukur seperti pekarangan, hiburan, penerangan, bahan bakar, sumber air dan Mandi Cuci Kakus (MCK). Rumah tangga yang berbatasan dengan mangrove di Desa Sidodadi memiliki rata-rata pekarangan dengan luas $<50 \mathrm{~m}^{2}$, hiburan di dalam rumah yang dimiliki adalah televisi, sumber penerangan menggunakan listrik, bahan bakar untuk memasak adalah gas (37\%) dan minyak tanah (63\%), sumber air berasal dari sumur, dan untuk kebutuhan MCK rumah tangga yang menggunakan kamar mandi sendiri (55\%) dan kamar mandi umum (45\%). Fasilitas suatu rumah dapat dijadikan sebagai cerminan dari status sosial masyarakat. Hasil penelitian menunjukkan bahwa terdapat (44\%) rumah tangga dengan fasilitas rumah tidak lengkap. Berdasarkan hasil analisis data Tabel 2, fasilitas rumah berpengaruh secara signifikan terhadap kemiskinan, artinya semakin menurun fasilitas rumah yang dimiliki maka akan meningkatkan kemiskinan. Umumnya pendapatan rumah tangga lebih cenderung digunakan untuk memenuhi kebutuhan pangan dibandingkan kebutuhan untuk fasilitas dalam suatu rumah.

Umur kepala rumah tangga berkisar antara 25-45 tahun. Kisaran umur tersebut merupakan umur produktif untuk bekerja. Umumnya seseorang yang berada pada umur produktif mampu memperoleh pendapatan yang lebih dibandingkan seseorang yang tidak termasuk pada umur produktif. Kelompok umur produktif secara fisik memiliki potensi yang besar untuk menghasilkan barang dan jasa (Putri, 2013). Tabel 2 menunjukkan bahwa umur 
bukan merupakan faktor yang mempengaruhi kemiskinan, ini berbeda dengan penelitian yang telah dilakukan (Wijaya, 2014) yang menyatakan bahwa dengan meningkatnya umur seseorang akan memberi pengalaman lebih dalam melakukan kegiatan ekonomi sehingga berpengaruh terhadap pendapatan. Faktor umur tidak berpengaruh secara signifikan terhadap tingkat kemiskinan di Desa Sidodadi, karena seluruh responden berada pada umur/usia produktif. Sehingga umur yang lebih tua atau yang lebih muda dalam kisaran usia produktif (15-60 tahun) kecil pengaruhnya $(\alpha=0,668)$ terhadap perbedaan tingkat kemiskinan. Sejalan dengan pendapat Zega (2013) bahwa umur tidak selamanya dijadikan sebagai acuan dalam memperoleh pendapatan.

Pekerjaan adalah segala sesuatu yang dikerjakan seseorang dengan tujuan untuk memenuhi kebutuhan hidup sehari-hari (Fadila, 2013). Jenis pekerjaan yang dianalisis dalam penelitian ini adalah nelayan dengan menggunakan variabel dummy. Hasil analisis data Tabel 2 menunjukkan bahwa jenis pekerjaan sebagai nelayan tidak berpengaruh secara signifikan terhadap tingkat kemiskinan. Ini dimungkinkan karena nelayan di Desa Sidodadi memiliki jam kerja yang relatif singkat dan hanya mengandalkan musim pada saat mencari ikan, kondisi tersebut berdampak pada hasil tangkapan yang tidak optimal sehingga mengakibatkan tingkat produksi dan pendapatan yang rendah. Untuk mencukupi kebutuhannya beberapa masyarakat melakukan pekerjaan lain yaitu sebagai buruh bangunan, penyewaan perahu dan pedagang. Nelayan umumnya adalah masyarakat suku/etnis bugis yang menjadikan pekerjaan tersebut sebagai pekerjaan utama. Sedikit responden (19\%) yang memilih bekerja sebagai nelayan, ini dikarenakan rendahnya pendidikan yang dimiliki, sulitnya memperoleh modal untuk melakukan usaha dan merupakan pekerjaan yang dilakukan secara turun temurun. Pekerjaan utama responden selain nelayan adalah bekerja sebagai Pegawai Negeri Sipil (8\%), petani (18\%), buruh (35\%) dan pedagang $(20 \%)$.

Kesehatan diukur berdasarakan berapa kali responden terjangkit penyakit. Berdasarkan hasil penelitian diketahui bahwa kesehatan memiliki pengaruh yang kecil $(\alpha=0,247)$ terhadap tingkat kemiskinan. Ini dimungkinkan dengan sudah terdapatnya pelayanan kesehatan seperti puskesmas, puskesdes dan bidan, sehingga masyarakat memiliki akses yang mudah untuk melakukan pengobatan. Apabila terdapat masyarakat yang terjangkit penyakit, pengobatan dapat segera dilakukan sehingg masyarakat dapat kembali melakukan aktivitas pekerjaanya.

Kondisi rumah pada penelitian ini dilihat dari beberapa tolak ukur seperti jenis atap, bilik, status rumah, luas dan lantai. Rumah tangga yang berbatasan dengan hutan mangrove di Desa Sidodadi 45\% menggunakan genteng untuk atap rumahnya, kondisi bilik $43 \%$ menggunakan tembok, status rumah $37 \%$ rumah pribadi, luas rumah $73 \%$ memiliki luas tanah 90-120 $\mathrm{m}^{2}$ dan lantai rumah $55 \%$ menggunakan plester/semen. Berdasarkan hasil penelitian diketahui bahwa kondisi rumah tidak berpengaruh secara signifikan terhadap kemiskinan. Umumnya rumah tangga yang berbatasan dengan hutan mangrove merupakan warga pendatang yang bekerja dalam proyek pembangunan tambak di Desa Sidodadi, sehingga masyarakat membangun rumah untuk dijadikan sebagai tempat tinggal dan menetap di desa tersebut.

\section{SIMPULAN}

Rumah tangga yang tinggal berbatasan dengan hutan mangrove di Desa Sidodadi sebagian $(45 \%)$ masih tergolong miskin. Kemiskinan yang terjadi tidak dipengaruhi oleh umur, jenis pekerjaan, kesehatan, suku/etnis dan kondisi rumah. Karakteristik rumah tangga yang berpengaruh terhadap kemiskinan di Desa Sidodadi adalah pendidikan, pendapatan, jumlah anggota keluarga yang bekerja dan fasilitas rumah. Rumah tangga tidak banyak memiliki alternatif sumber pendapatan akibat rendahnya pengetahuan masyarakat mengenai pemanfaatan hasil hutan bukan kayu dari hutan mangrove. 


\section{DAFTAR PUSTAKA}

Agunggunanto, E. F. 2011. Analisis kemiskinan dan pendapatan keluarga nelayan kasus di Kecamatan Wedung Kabupaten Demak Jawa Tengah Indonesia. Jurnal Dinamika Ekonomi Pembangunan. 1 (1): 50-58.

Aminah, L. N. 2013. Kontribusi Hutan Rakyat Terhadap Pendapatan Rumah Tangga Petani di Desa Buana Bakti Lampung Timur. Skripsi (Tidak Dipublikasikan). Fakultas Pertanian. Universitas Lampung. Bandar Lampung. 65 p.

Fadila, A. C. 2013. Pengaruh status sosial ekonomi orang tua terhadap prilaku anak. Jurnal Sociologie. 1 (4): 262-269.

Indriyanto. 2008. Ekologi Hutan. Buku. PT. Bumi Aksara. Jakarta. 210 p.

Iskandar. 2007. Faktor-faktor yang mempengaruhi kesehatan keluarga. Jurnal Ekologi. 1 (1): 133-141.

Kaplale, R. 2012. Faktor-faktor yang mempengaruhi tingkat kemiskinan di Kota Ambon. Jurnal Agrilan. 1 (1): 101-115.

Kornita, S. E dan Yusbar Y. 2011. Strategi bertahan hidup (libe survival strategy) penduduk miskin Kelurahan Batu Teritip Kecamatan Sungai Sembilan. Jurnal Ekonomi. 19 (4): $57-72$.

Patang. 2012. Analisis strategi pengelolaan hutan mangrove studi kasus di Desa TongkeTongke Kabupaten Sinjai. Jurnal Agrisistem. 8 (2): 100-109.

Pratama, Y. C. 2014. Analisis faktor-faktor yang mempengaruhi kemiskinan di Indonesia. Jurnal Bisnis dan Manajemen. 4 (2): 210-223.

Purwanti, E. 2014. Pengaruh jumlah tanggungan keluarga, pendapatan terhadap partisipasi kerja wanita pada industri kerupuk kedelai di Tuntang Kabupaten Semarang. Jurnal Among Makarti. 7 (13): 113-123.

Putri, A. D dan Nyoman D. S. 2013. Pengaruh umur, pendidikan, pekerjaan terhadap pendapatan rumah tangga miskin di Desa Bebandem. Jurnal Ekonomi Pembangunan. 2 (2): $173-180$.

Sajogyo. 2006. Ekososiologi Deideologisasi Teori, Restrukturisasi Aksi. Buku. Cindelaras Pustaka Rakyat Cerdas. Yogyakarta. 516 p.

Sugiharto, E. 2007. Tingkat kesejahteraan masyarakat nelayan Desa Benua Baru Ilir berdasarkan indikator Badan Pusat Statistik. Jurnal Ekonomi Pembangunan dan Perencanaan. 4 (2): 32-36.

Wahyukinasih, M. H., C. Wulandari. dan S. Herwanti. 2014. Analisis kelayakan usaha berbasis hasil hutan bukan kayu ekosistem mangrove di Desa Margasari Lampung Timur. Jurnal Sylva Lestari. 2 (2): 41-48p.

Wijayanti, L dan Ihsannudin. 2013. Strategi peningkatan kesejahteraan masyarakat nelayan Kecamatan Pademawu Kabupaten Pamengkasan. Jurnal Agriekonomika. 2 (2): 1-12.

Zega, S. B. 2013. Analisis pengelolaan agroforestry dan kontribusinya terhadap perekonomian masyarakat. Jurnal Peronema Forestry Science. 2 (2): 152-162. 